\begin{tabular}{|l|l|l|l|l|l|l|l|l|l|l|}
\hline \multirow{2}{*}{ SPi } & \multicolumn{4}{|c|}{ Journal Code: } & \multicolumn{4}{|c|}{ Article ID } & Dispatch 15.05.15 & CE: Roblina Joy M. Sagolili \\
\cline { 2 - 9 } & $\mathrm{H}$ & $\mathrm{E}$ & $\mathrm{C}$ & & 3 & 2 & 0 & 6 & No. of Pages: 17 & ME: \\
\hline
\end{tabular}

HEALTH ECONOMICS

Health Econ. (2015)

Published online in Wiley Online Library (wileyonlinelibrary.com). DOI: 10.1002/hec.3206

\title{
ATTRITION BIAS IN PANEL DATA: A SHEEP IN WOLF'S CLOTHING? A CASE STUDY BASED ON THE MABEL SURVEY
}

\author{
TERENCE C. CHENG ${ }^{\mathrm{a}, *}$ and PRAVIN K. TRIVEDI ${ }^{\mathrm{b}, \mathrm{c}}$ \\ ${ }^{\mathrm{a}}$ The University of Adelaide \\ ${ }^{\mathrm{b}}$ University of Queensland \\ ${ }^{\mathrm{c}}$ Indiana University - Bloomington
}

\section{SUMMARY}

This paper investigates the nature and consequences of sample attrition in a unique longitudinal survey of medical doctors. We describe the patterns of non-response and examine if attrition affects the econometric analysis of medical labour market outcomes using the estimation of physician earnings equations as a case study. We compare the econometric gestimates obtained from a number of different modelling strategies, which are as follows: balanced versus unbalanced samples; an attrition model for panel data based on the classic sample selection model; and a recently developed copula-based selection model. Descriptive evidence shows that doctors who work longer hours, have lower years of experience, are overseas trained and have changed their work location are more likely to drop out. Our analysis suggests that the impact of attrition on inference about the earnings of general practitioners is small. For specialists, there appears to be some evidence for an economically significant bias. Finally, we discuss how the top-up samples in the Medicine in Australia: Balancing Employment and Life survey can be used to address the problem of panel attrition. Copyright (C) 2015 John Wiley \& Sons, Ltd.

Received 12 May 2014; Revised 23 April 2015; Accepted 29 April 2015

JEL Classification: C23; J31; I11

KEY WORDS: attrition; medical doctors; earnings; copula

\section{INTRODUCTION}

This paper investigates sample attrition in a unique longitudinal survey of medical doctors. The availability of longitudinal data has allowed researchers on health and health economics to investigate a wide range of research questions that would otherwise not be possible using cross-sectional data. Some examples of longitudinal data on health include social surveys such as the Survey of Health, Ageing and Retirement in Europe, and in the form of administrative datasets such as population registers, hospital records and insurance reimbursement claims. ${ }^{1}$

A key limitation of longitudinal data is the problem of non-response and attrition. Panel attrition is essentially the loss of data. Such attrition is usually cumulative so that after a few rounds of survey, the total data loss can be a significant proportion of the original sample. Whether such data loss seriously impacts statistical inference based on regression analysis depends upon the pattern of missingness. If the data are missing at random, then the panel remains representative of the underlying population but the sample size becomes smaller.

\footnotetext{
*Correspondence to: The University of Adelaide. E-mail: terence.cheng @ adelaide.edu.au

${ }^{1}$ See Jones (2007) for an extensive list of longitudinal surveys used in applied research on health economics.
} 
In this case, the population conditional regression function can be identified and estimated consistently; however, the estimates are inefficient relative to those based on the full sample. If the pattern of missingness is such that the sample is not representative of the population, then the conditional regression function is not identified and cannot be estimated consistently. Concern with the inferential impact of sample attrition is based on a suspicion that the missing observations were 'selected out' of the sample according to a mechanism. The distortion in the inference on the conditional regression function, or some component thereof, induced by such a mechanism is referred to as attrition (or selection) bias.

A number of approaches to handle attrition exist, and their use depends on the assumptions made about the origins and causes of the missing data problem. If the data are assumed to be missing at random (MAR), reweighting using post-stratification weights can be used to adjust for the non-response. Alternatively, inverse probability weighting can be applied, which involves estimating the probability of response as a function of observed characteristics (Fitzgerald et al., 1998; Jones et al., 2004). If the data are not MAR, attrition may be accommodated by modelling the non-response simultaneously with the outcomes of interest (Hausman and Wise 1979; Wooldridge 2010). These model-based methods usually require strong and often untestable assumptions. An alternative is the use of refreshment samples that can provide additional information about the attrition process, allowing for more robust and precise estimation than relying solely on conventional methods (Ridder, 1992; Hirano et al., 2001).

In this paper, we investigate the nature and consequences of attrition in the Medicine in Australia: Balancing Employment and Life (MABEL) longitudinal survey of doctors. If attrition leads to a random loss of data, then by definition such loss will not lead to sample selection bias. Hence, a natural way to investigate the effects of attrition is to design a test of the hypothesis that a data have a MAR property. We do so in several ways. We first compare the results from balanced and unbalanced samples, which we would not expect to significantly differ if the MAR assumption is valid. Following a conventional approach, we then specify a selection model for panel data and test whether there is a statistically significant selection effect. To test some of the potential limitations of this approach, we also use a recently developed copula-based framework to test if the conclusions based on the selection model are robust to alternative formulations. MABEL also makes available a top-up sample during each wave after the first, which in turn generates a top-up panel of its own. These additional panels also support further tests of the MAR assumption. Jointly, the various components provide a comprehensive investigation of the importance of attrition.

We investigate if the attrition in the MABEL survey affects the econometric analysis of medical labour market outcomes using the estimation of general practitioners (GPs) and medical specialists earnings equations. The determinants of doctors' earnings were analysed recently by Morris et al. (2011) and Cheng et al. (2011) and have been studied in the context of the effect of earnings on hours worked, job satisfaction (Ikenwilo and Scott, 2007), the choice of working in the public or private sector (Sæther, 2005) and gender differentials (Gravelle et al., 2011). A unifying feature in these studies is the reliance on cross-sectional data. Several recent studies employed panel data (Baltagi et al. 2005, Sasser 2005, Andreassen et al. 2013), but did not explicitly consider the effects of attrition. We focus our inquiry on the elasticity of earnings with respect to hours worked, which have been shown to be important in explaining earnings (Schurer et al. 2012, Gravelle et al. 2011).

The remainder of the paper is organised as follows. Section 2 describes the MABEL survey and assesses the extent of, and reasons for, sample attrition. Section 3 discusses the estimation strategy for modelling attrition. Section 4 discusses the econometric estimates of the attrition function and the estimated hours elasticity on doctors earnings using the original 2008 cohort of doctors. Section 5 analyzes attrition in the top-up samples in MABEL and discusses the issues involved in using the top-up samples. Finally, Section 6 summarises our key findings.

\section{THE MABEL LONGITUDINAL SURVEY OF DOCTORS}

The MABEL survey is a longitudinal survey of Australian doctors that began in 2008. The aim of the survey is to investigate factors influencing workforce participation, labour supply, specialty choice and mobility of 
doctors. The survey covers four broad groups within the medical workforce, which are as follows: GPs (primary care practitioners); medical specialists; specialists-in-training (e.g. registrars); and hospital non-specialists. The sample frame is the Australian Medical Publishing Company's (AMPCo) Medical Directory, a national database managed by the Australian Medical Association.

The original cohort comprises 10498 doctors working in clinical practice in Australia, representing more than 19 per cent of the clinically active population of Australian doctors in 2008. This cohort was shown to be nationally representative with respect to age, gender, geographic location and hours worked (see Joyce et al. (2010) for a description of the cohort and survey methods). Approximately 80 per cent of all doctors in the 2008 cohort are GPs $(N=3906)$ and specialists $(N=4596)$. From the second and subsequent waves, top-up samples comprising mainly of new entrants to the medical workforce are included to maintain the cross-sectional representativeness of the survey. These doctors are predominantly junior doctors - hospital non-specialists and specialists-in-training.

\subsection{Non-response in the Medicine in Australia: Balancing Employment and Life survey}

Doctors in each cohort are defined as responders if they complete a survey questionnaire in any subsequent wave of the survey. Responding doctors can either be in clinical practice or not in clinical practice at the time of the survey. Those not undertaking clinical practice were only asked about their current status (e.g. maternity leave and working outside of Australia) and their intentions on resuming clinical work in Australia. A doctor is a nonrespondent in a subsequent wave if he/she fails to complete or return the survey questionnaire. Non-response can arise from refusal to respond or cooperate; absence of a valid contact address; declining to participate; or death of a study subject.

Table I describes the distribution of responders and attritors among GPs and specialists in the 2008 cohort across the first four waves of the MABEL survey. Conditional attrition rate, defined as the ratio of the number of drop-outs in wave $t$ and the number of respondents in wave $t-1$, is the highest between the first and second waves. 21.5 per cent and 20.2 per cent of GPs and specialists respectively in the original cohort did not respond in the second year. By the end of the fourth year, 65.4 per cent of GPs and 66.8 per cent of specialists remained in the survey, with cumulative attrition rates of 34.6 per cent and 33.2 per cent. The overall survival rate across all four doctor groups (including specialists-in-training and hospital non-specialists) in the 2008 cohort after four years is 65.9 per cent (Yan et al., 2013).

A significant fraction of attriting doctors re-enter the study in a subsequent wave. This can be seen from the last column of Table I, which shows the number of rejoiners - doctors who are non-respondents in wave $t-1$ and responded in wave $t$. Approximately 23 to 32 per cent of drop-outs in a previous wave responded to the next wave. A possible explanation for the high rejoiner rate is that changes in work (or residential) address can result in doctors being not contactable. This may arise if the AMPCo database does not have information on

Table I. Responders and attritors in Medicine in Australia: Balancing Employment and Life - 2008 cohort

\begin{tabular}{|c|c|c|c|c|c|c|c|c|c|}
\hline Year & $\begin{array}{l}\text { Number of } \\
\text { doctors }\end{array}$ & $\begin{array}{l}\text { Clinical } \\
\text { practice }\end{array}$ & $\begin{array}{l}\text { Non-clinical } \\
\text { practice }\end{array}$ & $\begin{array}{c}\text { Total } \\
\text { responders }\end{array}$ & $\begin{array}{l}\text { Survival } \\
\text { rate }(\%)\end{array}$ & $\begin{array}{c}\text { Total } \\
\text { attritors }\end{array}$ & $\begin{array}{l}\text { Conditional } \\
\text { attrition } \\
\text { rate }(\%)\end{array}$ & $\begin{array}{c}\text { Cumulative } \\
\text { attrition } \\
\text { rate }(\%)\end{array}$ & Rejoiners \\
\hline & & & & eneral practi & ners - & & & & \\
\hline 1 & 3906 & 3906 & & & 100 & & & & \\
\hline 2 & 3066 & 2954 & 112 & 3066 & 78.5 & 840 & 21.5 & 21.5 & \\
\hline 3 & 2824 & 2723 & 101 & 2824 & 72.3 & 1082 & 12.8 & 27.7 & 270 \\
\hline \multirow[t]{2}{*}{4} & 2554 & 2470 & 84 & 2554 & 65.4 & 1352 & 13.0 & 34.6 & 247 \\
\hline & & & & — Specialis & & & & & \\
\hline 1 & 4596 & 4596 & & & 100 & & & & \\
\hline 2 & 3670 & 3491 & 179 & 3670 & 79.9 & 926 & 20.2 & 20.2 & \\
\hline 3 & 3367 & 3187 & 180 & 3367 & 73.3 & 1229 & 12.3 & 26.7 & 270 \\
\hline 4 & 3068 & 2919 & 149 & 3068 & 66.8 & 1528 & 12.7 & 33.2 & 290 \\
\hline
\end{tabular}


the most recent address despite being updated regularly. Correspondingly, these doctors who were previously non-responders are likely to rejoin the survey when their addresses in the database have been updated. Indicative evidence can be observed from the data, where in wave 3, 8.4 per cent of those have moved from a different postal area are rejoiners compared with 5.6 per cent for those who had not moved. As we will explain in Section 3 , it is usual to exclude rejoiners from the econometric analysis.

Analysis of the patterns of attrition suggest that the relationship between attrition, earnings and hours worked is not straightforward and varies by doctor type. This is shown in Table A.1 in the Appendix, which presents the conditional attrition rates by annual earnings and hours worked at wave t-1. For GPs, attrition rates in year 2 are lowest for doctors in the first and fifth earnings quintiles. This relationship is reversed for specialists where attrition rates are highest for doctors with the lowest and highest earnings. Given that higher annual earnings can result from doctors working a larger number of hours, or having a high implied hourly earnings rate, attrition rates by annual hours worked are also presented to provide a more complete picture. The average attrition rate is higher in the top two quintiles of hours worked than in the bottom two quintiles, although there is some year-to-year variation.

Attrition rates also differ by doctors' characteristics. For both GPs and specialists, doctors who are male, are less experienced (and younger), self-employed and have changed postcodes are more likely to drop out across the four waves of the survey (Table A.2). The likelihood of dropping out is also positively associated with the length of time doctors' take to complete and return the survey in the preceding wave, that is, attrition appears to be a limiting form of procrastination.

\section{ECONOMETRIC STRATEGY}

The literature on panel attrition has several alternative approaches for handling the potential selection biases that might ensue from it. Whether selection bias is a serious concern may well depend upon the variable under study, and hence, conclusions will necessarily be qualified.

Under the assumption that attrition leads to observations missing at random, we would not expect that the resulting unbalanced sample will generate significantly different estimates from a balanced subsample. A comparison of the two sets of results then can provide a basis of a Hausman-type test for selection bias without having to identify the attrition function (Nijman and Verbeek, 1992). In the same spirit, using a refreshment sample if one is available to replace the missing observations with similar ones from the same population will also reduce or eliminate selection bias without having to identify the attrition function (Hirano et al., 2001). Imputation of missing values has a similar objective, but doing so without an attrition function is difficult.

There are two econometric alternatives that are less restrictive than the MAR assumption. The first is to assume that missingness depends upon some observable attributes which are included among the regressors in the outcome equation; this is the selection-on-observables model. The presence of these regressors controls for attrition and avoids attrition bias. A second, less strong assumption is to use a standard variant of the selection-on-unobservables model in which it allows for potential dependence/correlation between the unobserved factors in the attrition equation and the outcome equation. A widely used approach to modelling such dependence is to assume that the two errors have a bivariate normal distribution. It is commonly assumed that for robust identification of the outcome equation, the attrition equation should include a non-trivial exogenous regressor that is excluded from the outcome equation, a modelling feature usually referred to as 'exclusion restriction'. This viewpoint is widely shared even though identification may also be secured via a robust non-linearity in the attrition equation, a modeling feature usually referred to as identification via 'functional form restriction'. The advantage of the latter is that an exclusion restriction is not needed, although the issue of the functional form of the non-linearity remains open.

In this paper, both variants of the selection-on-unobservables will be used. For the second variant, we rely on the recently developed copula-based approach to modelling selection (Smith, 2003; Hasebe, 2013). In addition 
to not requiring a robust exclusion restriction, the copula-based model permits us to model dependence in a manner more flexible than bivariate normality. Details are given in Section 4.

\subsection{Selection-based panel attrition model}

The formal structure of the attrition model for panel data, consisting of the selection equation and the outcome equation, is similar to that of the classic sample selection model:

$$
\begin{aligned}
A_{i t}^{*} & =\mathbf{z}_{i t}^{\prime} \boldsymbol{\gamma}+\varepsilon_{1 i t}, \\
y_{i t}^{*} & =\mathbf{x}_{1 i t}^{\prime} \boldsymbol{\beta}_{1}+\mathbf{x}_{2 i}^{\prime} \boldsymbol{\beta}_{2}+\alpha_{i}+\varepsilon_{2 i t},
\end{aligned}
$$

where $\left(A_{i t}^{*}, y_{i t}^{*}\right)$ are latent variables, $\mathbf{z}_{i t}^{\prime}$ is a vector of exogenous regressors, $\alpha_{i}$ denotes the unobserved individual-specific effect and the component $\mathbf{x}_{1 i t}$ consists of time-varying regressors and the component $\mathbf{x}_{2 i}$ consists of time-invariant regressors whose components may overlap with $\mathbf{z}_{i t}$; the equation errors $\left(\varepsilon_{1 i t}, \varepsilon_{2 i t}\right)$ may be correlated. $A_{i t}$ takes the value 1 if the subject who responded to the survey questionnaire at $t-1$ does not respond at time $t$, and takes the value 0 otherwise, that is, $A_{i t} \equiv 1\left[A_{i t}^{*}>0 \mid \mathbf{z}_{i t}, A_{i t-1}=1\right]$. We assume that if $A_{i t}^{*}<0$, then $A_{i t+j}^{*}<0$, for all $j \geq 1$. The outcome variable is only observed for survey respondents ('non-attritors'), that is, $y_{i t}=y_{i t}^{*}$ if $A_{i t}^{*}>0$ and is missing if $A_{i t}^{*} \leq 0$. The probit regression is a common specification of the attrition function, that is, $\operatorname{Pr}\left[A_{i t} \equiv 1 \mid \mathbf{z}_{i t}, A_{i t-1}=1\right]=\Phi\left[\mathbf{z}_{i t}^{\prime} \gamma\right]$.

If the correlation between $\left(\varepsilon_{1 i t}, \varepsilon_{2 i t}\right)$ is zero, then the pair $\left(A_{i t}^{*}, y_{i t}^{*}\right)$ will be conditionally uncorrelated; the individual specific-effect $\alpha_{i}$ may be treated either as a correlated (with the $\mathbf{x}_{1 i}$ ) effect or an uncorrelated effect, a point that will be discussed further in the succeeding sections. Under non-correlation assumption, the missingness structure is said to be MAR type, in which case the outcome equation can be consistently estimated independently of the attrition equation.

Ignoring correlation or dependence between $\varepsilon_{1}$ and $\varepsilon_{2}$, if it exists, results in selection bias. A number of panel data estimators that control for selection are available (Wooldridge (2010, chapter 19.9). This set includes parametric estimators, which assume that $\left(\varepsilon_{1 i t}, \varepsilon_{2 i t}\right)$ have joint normal distribution, as well as the semiparametric two-step estimator that makes a sample selection adjustment. As in the case of the classic selection model for cross-section data, robust identification of the parameter $\boldsymbol{\beta}_{1}$ outcome requires that the attrition equation contains some non-trivial regressors that do not directly affect the outcome. One potential difference from the cross-sectional case, however, comes from the possibility that the set of instruments can vary over $t$.

We assume that the individual specific effect $\alpha_{i}$ is (a 'fied effect' ) correlated with the regressors in the outcome equation. Fixed effects ('incidental parameters') in linear models can be eliminated by first-difference or the so-called within transformation. The first-differencing transformation leads to a greater loss of observations because the range of $t$ now starts at $t=2$. But it also implies some analytical simplicity. Rewriting the previous equation in terms of first differences, we have

$$
y_{i t}-y_{i, t-1}=\left(\mathbf{x}_{1, i t}^{\prime}-\mathbf{x}_{1 i, t-1}^{\prime}\right) \boldsymbol{\beta}_{1}+\left(\varepsilon_{2, i t}-\varepsilon_{2, i t-1}\right) .
$$

To facilitate two-step estimation of the aforementioned equation, the error term $\varepsilon_{2, i t}$ is expressed in terms of its conditional expectation as follows:

$$
\begin{aligned}
\varepsilon_{2, i t} & =\mathrm{E}\left[\varepsilon_{2, i t} \mid \varepsilon_{1, i t}\right]+\eta_{i t}, \\
& =\sigma_{12} \lambda_{i t}\left(\mathbf{z}_{i t}^{\prime},\right)+\eta_{i t},
\end{aligned}
$$

where $\eta_{i t}$ is an independent and identically distributed error term, $\lambda_{i t}\left(\mathbf{z}^{\prime} \boldsymbol{\gamma}\right)$ denotes the attrition hazard (aka inverse Mills ratio) and $\sigma_{12}$ denotes the covariance between $\left(\varepsilon_{1 i t}, \varepsilon_{2 i t}\right)$. A consistent estimator of $\lambda_{i t}\left(\mathbf{z}^{\prime} \boldsymbol{\gamma}\right)$, denoted $\widehat{\lambda}_{i t}$, is generated by the probit equation for the attrition event. Then the equation 


$$
y_{i t}-y_{i, t-1}=\left(\mathbf{x}_{1, i t}^{\prime}-\mathbf{x}_{1 i, t-1}^{\prime}\right) \boldsymbol{\beta}_{1}+\sigma_{12} \widehat{\lambda}_{i t}+\left[\eta_{i t}+\left(\varepsilon_{2, i t}-\varepsilon_{2, i t-1}\right)+\sigma_{12}\left(\lambda_{i t}-\widehat{\lambda}_{i t}\right)\right]
$$

where the three terms inside the square brackets define the composite error on the outcome equation. Under the assumption that all elements of $\mathbf{x}_{1, i t}^{\prime}$ are uncorrelated with the composite error term, the least squares estimator is a consistent estimator with a complicated asymptotic variance because $\widehat{\lambda}_{i t}$ is a generated regressor, and, moreover, the structure of the error implies serial correlation as well as heteroskedasticity.

In a panel data setting, it is not necessary to assume that $\gamma$ is constant across different panel waves. The attrition equation may be estimated for each wave separately, say, using the probit specification $\operatorname{Pr}\left[A_{i t} \mid \mathbf{z}_{i t}, A_{i, t-1}=\right.$ $1]=\Phi\left(\mathbf{z}_{i t}^{\prime} \gamma_{t}\right)$, which in turn would generate the time varying attrition hazard $\Phi\left(\mathbf{z}_{i t}^{\prime} \gamma_{t}\right)$. The outcome equation given earlier can be generalised to include an estimated $\lambda$-term for each wave.

An alternative specification is that in which one or more elements of $\mathbf{x}_{1 i t}$ is endogenous, in which case an instrumental variable or generalized method of moments-type estimator would be preferred. The usual caveats regarding the choice of instruments will apply.

In the aforementioned framework, a test of the null hypothesis of MAR against the alternative of selection bias may be based on $H_{0}: \sigma_{12}=0$ versus $H_{1}: \sigma_{12} \neq 0$. Given quite strong assumptions involved in its implementation and the complexity of the robust variance estimator, the outcome of the test should be treated with caution. As mentioned earlier, there are other alternatives for testing this hypothesis, although these too have limitations. The outcome equation could be estimated using inverse probability weights (IPW) - an approach that does not require us to identify the attrition function. But IPW may generate imprecise results if the probability model does not include good proxies for the unobservables that affect the outcome and also determine selection (Wooldridge 2010, p.822). Another approach (Nijman and Verbeek, 1992) is to compare results based on balanced and unbalanced panels. While a formal Hausman-type test has been suggested based on such a comparison, the validity of the test is questionable without making strong assumptions. Yet, another option which we consider in Section 5 uses a refreshment or a matched top-up sample to replace the missing attritors. Implementation of this approach is not practical for our data set as we explain in Section 5.

\subsection{Copula-based approach to selection}

This paper's empirical analysis of attrition within the framework of a selection model has three important limitations that apply to this genre of specifications. First, the methodology of controlling for selection relies on the restrictive assumption of bivariate normality. Second, it requires that we have a non-trivial excluded exogenous variable, which serves to identify the role of attrition. Third, its test of selection is based only on a linear measure of dependence (correlation) between unobserved factors that simultaneously impact both attrition and earnings.

To address these limitations, we also estimated our model using the recently developed copula-based estimator, which relaxes the normality assumption and does not need any exclusion restrictions. A fully parametric copula-based approach (based on Sklar's Theorem) requires that we specify the marginal distributions ('margins') of the attrition and earnings variables, denoted $f(A \mid \bullet)$ and $f(y \mid \bullet)$ (where conditioning variables are suppressed for notional simplicity), respectively, and then combined using a specified parametric copula, denoted $C[f(A \mid \bullet), f(y \mid \bullet), \Theta]$ where $\Theta$ is a scalar-valued dependence parameter. This generates a joint distribution of $A$ and $y$ (with a dependence parameter) that may be estimated by maximum likelihood. We estimated the copula selection model using the Stata program heckmancopula developed by Hasebe (2013).

The flexibility of the approach comes from the feasibility of varying both the margins, that is, $f(A \mid \bullet)$ and $f(y \mid \bullet)$, and the functional form of the copula, $C[\bullet]$. Further, provided the margins are sufficiently flexible, this approach potentially covers a wider range of dependence structures than possible under normal distribution. Specifically, one can model asymmetric or symmetric tail dependence. Sample selection effect is such that a model takes on a more general form. 
The advantages of the copula-based approach were mentioned earlier in this section. A limitation of the approach concerns the choice of the copula function out of a set of many possible one. This disadvantage is mitigated if we consider several combinations of copulas and alternative specifications of the marginal distributions and choose the 'best' model according to a specified criterion. This is the approach followed. The marginal for attrition, a binary variable, is straight-forward, probit or logit; that for log(income) is more open. We have considered a set of alternatives that includes the log-normal, log-logistic, Student's $t$. The final choice between these alternative model specifications is based on the penalised log-likelihood criterion. We discuss the details of the exercise in Section 4.

\section{RESULTS}

\subsection{Physician earnings model}

The dependent variable of interest in the econometric analysis is the logarithm of annual gross (pre-tax) earnings of GPs and specialists. We examine annual earnings as opposed to hourly wages because an earnings model of hourly wages is misspecified if earnings are not proportional to hours worked (Cheng et al., 2011; Gravelle et al., 2011). Given that total earnings are increasing in working hours, we include annual hours worked an explanatory variable, which is constructed using information on total weekly hours worked and the number of weeks worked per year.

In addition to hours worked, we include doctors' personal characteristics and a set of human capital variables such as doctors education and professional qualifications, experience and medical specialty for specialists. Given that employment mode and practice characteristics are likely to influence earnings, we include variables on self-employment, GP practice size and whether they undertake hospital work and the fraction of time in clinical work by specialists. We also include a set of state and territory indicators and measures of remoteness to control for local area characteristics. The sample characteristics, by attrition status, are presented in Table A.3.

The set of explanatory variables described earlier are included in the attrition function and the outcome equation. As indicated in Section 3, identification of the parameters in the outcome equation requires that the attrition function contains regressors (or instruments) that influence the likelihood of non-response but do not have a direct effect on earnings. We explained earlier that doctors who change postcodes are more likely to drop out; this is not a viable instrument if doctors move by switching into better paying jobs. Instead, we use the length of time (in days) that respondents took to return a hardcopy survey or complete an online questionnaire, which we showed in Table A.2, is negatively associated with the likelihood of dropping out in the next wave, but is not expected to have a direct effect on earnings.

\subsection{Estimates of the attrition function}

Table II shows the estimates from the sequential response probit regressions for GPs and specialists. The estimates are from a 'pooled' model whereby the sequential response function of each wave $t$ is pooled across waves 2 to 4 to maximise statistical power and estimated using covariates observed at wave $t-1$.

For GPs, the results show a statistically significant relationship between the probability of response with the country of medical training, length of work experience and practice size. All else being equal, GPs that are trained in Australia have a higher probability of responding compared with their overseas trained counterparts. Doctors with more years of experience are also more likely to respond compared with those with less than 10 years since graduating from medical school. GPs from larger practices are also more likely to respond compared with solo practitioners. The length of response time in the preceding survey wave is significantly related to the likelihood of non-response. GPs who took a longer time to respond are more likely to drop out in the next wave. Conditional on the other covariates that influence the likelihood of response, there is no statistically significant relationship between non-response and hours worked. 
Table II. Estimates from pooled sequential response regressions for general practitioners and specialists

\begin{tabular}{|c|c|c|c|c|}
\hline & \multicolumn{2}{|c|}{ General practitioners } & \multicolumn{2}{|c|}{ Specialists } \\
\hline & Coeff. & Std Err. & Coeff. & Std Err. \\
\hline Log(Annual Hours) & -0.06 & 0.05 & -0.04 & 0.05 \\
\hline Female & 0.07 & 0.05 & 0.03 & 0.05 \\
\hline Temporary visa & 0.14 & 0.14 & -0.29 & 0.20 \\
\hline Australian medical school & $0.18 * * *$ & 0.05 & 0.06 & 0.05 \\
\hline Fellow & 0.07 & 0.04 & 0.15 & 0.10 \\
\hline Number of postgraduate qual. & 0.04 & 0.03 & 0.02 & 0.04 \\
\hline Do hospital work & -0.05 & 0.05 & & \\
\hline Percentage clinical work & & & 0.0001 & 0.001 \\
\hline Self-employed & 0.002 & 0.002 & $-0.07^{*}$ & 0.04 \\
\hline \multicolumn{5}{|l|}{ Experience (Excl: $<10$ years) } \\
\hline $10-19$ years & $0.30 * * *$ & 0.07 & 0.06 & 0.06 \\
\hline 20-29 years & $0.32 * * *$ & 0.07 & $0.17 * * *$ & 0.06 \\
\hline 30-39 years & $0.38 * * *$ & 0.08 & $0.18 * * *$ & 0.06 \\
\hline$\geq 40$ years & $0.29 * * *$ & 0.10 & $0.22 * * *$ & 0.08 \\
\hline \multicolumn{5}{|l|}{ Practice size (Excl: Solo) } \\
\hline $2-3$ doctors & $0.21 * * *$ & 0.08 & & \\
\hline $6-9$ doctors & $0.17 * *$ & 0.07 & & \\
\hline$\geq 10$ doctors & $0.18 * *$ & 0.08 & & \\
\hline \multicolumn{5}{|l|}{ Specialty (Excl: Paediatrics) } \\
\hline Cardiology & & & -0.06 & 0.16 \\
\hline Gastroenterology & & & -0.03 & 0.15 \\
\hline General medicine & & & 0.05 & 0.14 \\
\hline Intensive care & & & -0.03 & 0.18 \\
\hline Thoracic medicine & & & -0.13 & 0.15 \\
\hline Int. med.: Other & & & -0.01 & 0.09 \\
\hline Pathology & & & -0.07 & 0.13 \\
\hline General surgery & & & -0.14 & 0.12 \\
\hline Orthopaedic surgery & & & -0.004 & 0.13 \\
\hline Surgery: Other & & & -0.09 & 0.11 \\
\hline Anaesthesia & & & 0.08 & 0.09 \\
\hline Diagnostic radiology & & & $-0.29 * *$ & 0.12 \\
\hline Emergency medicine & & & -0.03 & 0.11 \\
\hline Obstetrics/Gynaecology & & & -0.08 & 0.11 \\
\hline Ophthalmology & & & -0.17 & 0.13 \\
\hline Psychiatry & & & -0.09 & 0.10 \\
\hline Other & & & -0.15 & 0.11 \\
\hline \multicolumn{5}{|l|}{ State (Excl: New South Wales) } \\
\hline Victoria & -0.07 & 0.05 & 0.01 & 0.05 \\
\hline Queensland & -0.09 & 0.06 & -0.06 & 0.06 \\
\hline South Australia & $0.15^{*}$ & 0.08 & -0.11 & 0.13 \\
\hline Western Australia & -0.11 & 0.07 & -0.10 & 0.05 \\
\hline Tasmania & -0.07 & 0.12 & -0.05 & 0.06 \\
\hline Australian Capital Territory & $-0.27 *$ & 0.16 & 0.15 & 0.16 \\
\hline Northern Territory & 0.03 & 0.16 & -0.28 & 0.24 \\
\hline \multicolumn{5}{|l|}{ Remoteness (Excl: Major city) } \\
\hline Inner regional & 0.03 & 0.06 & $0.11 *$ & 0.06 \\
\hline Other & 0.03 & 0.07 & $0.22 *$ & 0.13 \\
\hline Time to response & $-3.55^{* * *}$ & 0.54 & $-2.15^{* * *}$ & 0.83 \\
\hline Time to response ${ }^{2}$ & $2.72 * * *$ & 0.42 & $1.53 * * *$ & 0.62 \\
\hline Constant & 0.22 & 0.44 & 0.26 & 0.64 \\
\hline Number of observations & \multicolumn{2}{|c|}{5166} & \multicolumn{2}{|c|}{2139} \\
\hline
\end{tabular}

For medical specialists, those with more years of experience, and those who took a shorter time to return or complete a survey, are more likely to respond in the next wave. The results also indicate that specialists practicing in regional areas are more likely to respond compared with those in major cities. The results also suggest that there are differences in the likelihood of response across different medical specialties. 


\subsection{Estimates of elasticity on hours}

Tables III and IV present the estimates on the elasticity on hours worked from the physician earnings equations for GPs and specialists, respectively. Columns (1) and (2) show the estimates from the fixed effect estimator ('within estimator') for the unbalanced and balanced samples, respectively. Columns (3) and (4) present the first differences estimators for the unbalanced and balanced samples. Column (5) shows the estimates from the first differences estimator where attrition is accommodated by the inclusion of the attrition hazard in the earnings equation as described in Section 3. In these models, the attrition hazard is allowed to vary across the different panel waves by interacting the hazard function estimated from the pooled attrition model with a set of wave dummies.

Table III. Earnings model for general practitioners -2008 cohort

\begin{tabular}{|c|c|c|c|c|c|c|}
\hline & $\begin{array}{l}\text { Unbalanced: } \\
\text { fixed } \\
\text { effects }\end{array}$ & $\begin{array}{l}\text { (2) } \\
\text { Balanced: } \\
\text { fixed } \\
\text { effects }\end{array}$ & $\begin{array}{l}\text { (3) } \\
\text { Unbalanced: } \\
\text { first } \\
\text { differences }\end{array}$ & $\begin{array}{l}\text { (4) } \\
\text { Balanced: } \\
\text { first } \\
\text { differences }\end{array}$ & $\begin{array}{l}\text { (5) } \\
\text { Attrition } \\
\text { adjusted }\end{array}$ & $\begin{array}{c}(6) \\
\text { Copula } \\
\text { selection } \\
\text { model }\end{array}$ \\
\hline Coefficient on hours & $\begin{array}{c}0.460 \\
(0.027)\end{array}$ & $\begin{array}{c}0.407 \\
(0.038)\end{array}$ & $\begin{array}{c}0.428 \\
(0.042)\end{array}$ & $\begin{array}{c}0.387 \\
(0.055)\end{array}$ & $\begin{array}{c}0.422 \\
(0.041)\end{array}$ & $\begin{array}{c}0.315 \\
(0.043)\end{array}$ \\
\hline $\begin{array}{l}\text { Wave-varying attrition hazards: } \\
\text { Wald test of joint significance }\left(\chi^{2}\right) \\
\text { Wald test: } p \text {-value } \\
\text { Degrees of freedom }\end{array}$ & & & & & $\begin{array}{l}42.47 \\
0.000 \\
3\end{array}$ & \\
\hline $\begin{array}{l}\text { Dependence in copula model: } \\
\text { Wald test of independence } \\
\text { Wald test: } p \text {-value }\end{array}$ & & & & & & $\begin{array}{l}1.862 \\
0.172\end{array}$ \\
\hline Number of observations & 7776 & 3464 & 4106 & 2598 & 4043 & 5166 \\
\hline
\end{tabular}

Robust-clustered standard errors used in columns (3) and (4). Bootstrapped standard errors in column (5). The total number of covariates is 25 . Additional covariates include visa status, hospital work, self-employment, experience, practice size, states/territory and remoteness. The copula selection model in column (6) is estimated using the Stata program heckmancopula developed by Hasebe (2013). The preferred copula selection model is based on Student $t$ marginal for logarithm of earnings, probit marginal for attrition and the Frank copula.

Table IV. Earnings model for specialists - 2008 cohort

\begin{tabular}{|c|c|c|c|c|c|c|}
\hline & $\begin{array}{l}\text { Unbalanced: } \\
\text { fixed } \\
\text { effects }\end{array}$ & $\begin{array}{l}\text { (2) } \\
\text { Balanced: } \\
\text { fixed } \\
\text { effects }\end{array}$ & $\begin{array}{l}\text { (3) } \\
\text { Unbalanced: } \\
\text { first } \\
\text { differences }\end{array}$ & $\begin{array}{l}\text { (4) } \\
\text { Balanced: } \\
\text { first } \\
\text { differences }\end{array}$ & $\begin{array}{l}\text { (5) } \\
\text { Attrition } \\
\text { adjusted }\end{array}$ & $\begin{array}{l}\text { (6) } \\
\text { Copula } \\
\text { selection } \\
\text { model }\end{array}$ \\
\hline Coefficient on hours & $\begin{array}{l}0.287 \\
(0.022)\end{array}$ & $\begin{array}{c}0.356 \\
(0.029)\end{array}$ & $\begin{array}{c}0.174 \\
(0.038)\end{array}$ & $\begin{array}{c}0.244 \\
(0.053)\end{array}$ & $\begin{array}{c}0.180 \\
(0.035)\end{array}$ & $\begin{array}{c}0.104 \\
0.026\end{array}$ \\
\hline $\begin{array}{l}\text { Wave-varying attrition hazards: } \\
\text { Wald test of joint significance }\left(\chi^{2}\right) \\
\text { Wald test: } p \text {-value } \\
\text { Degrees of freedom }\end{array}$ & & & & & $\begin{array}{l}38.65 \\
0.000 \\
3\end{array}$ & \\
\hline $\begin{array}{l}\text { Dependence in copula model: } \\
\text { Wald test of independence } \\
\text { Wald test: } p \text {-value }\end{array}$ & & & & & & $\begin{array}{r}7535.119 \\
0.000\end{array}$ \\
\hline Number of observations & 8904 & 4204 & 4921 & 3153 & 4875 & 6109 \\
\hline
\end{tabular}

Robust-clustered standard errors used in columns (3) and (4). Bootstrapped standard errors in column (5). The total number of covariates is 29 . Additional covariates include visa status, percentage of time in clinical practice, experience, self-employment, specialty, states/territory and remoteness. The copula selection model in column (6) is estimated using the Stata program heckmancopula developed by Hasebe (2013). The preferred copula selection model is based on the logistic marginal for log earnings, logit marginal for attrition and the Plackett copula. 
From Table III, the magnitude of the estimates from the fixed effect and first differences estimators where attrition is not explicitly modelled does not vary significantly, with the fixed effect estimate being slightly larger than the first differences estimate. The estimates from the balanced samples are slightly smaller compared with those from the unbalanced samples. These comparisons are informal and not necessarily superior to the Nijman-Verbeek test.

For the attrition adjusted estimates, a test of the null hypothesis that the wave-varying attrition hazard is jointly equal to zero is rejected. This result indicates that the MAR assumption is rejected, suggesting the presence of attrition or selection bias. Although the result suggests the presence of attrition bias, a comparison of the estimates from the first differences estimators with and without attrition adjustment reveals that these estimates are very similar in magnitude. This suggests that despite the presence of attrition bias, attrition in the MABEL survey does not have a significant impact on the estimates of earnings equations for GPs.

The estimates for the earnings model for medical specialists are presented in Table IV. As with the case for GPs, the fixed effect estimates are slightly larger compared with those from the first differences estimators. The estimates from the balanced samples are slightly larger than the unbalanced samples. For the attrition models where the constant is omitted from the attrition function, the null hypothesis that the wave-varying hazard is jointly equal to zero is rejected, suggesting the presence of attrition bias. Notwithstanding the difference in the findings on the presence of attrition bias, the estimate of the elasticity on hours is very similar across the variants of the first differences models. These results suggest, as with the case for GPs, that attrition does not have a significant effect on the estimation of earnings equations for specialists.

\subsection{Copula-based estimation}

Our copula-based application, as previously stated, requires a parametric assumption about the marginal distribution of the binary attrition variable and the continuous log(earnings) variable. We used the standard probit and logit specifications for the attrition dummy; for log(earnings) we used Gaussian, Student's $t$ (with degrees of freedom left as a free parameter) and logistic alternatives. The main attraction of the Student's $t$ distribution relative to the alternatives is that it can control for excess kurtosis (fat tails) that is a commonly reported feature of earnings.

We have used a suite of copulas to combine these margins including the Gaussian, Ali-Mikhail-Haq, FairlieGumbel-Morgenstern, Plackett, Gumbel, Clayton, Frank and Joe copulas; see Trivedi and Zimmer (2007) for additional details. The main differences between these alternative copulas are derive from their flexibility in capturing the type of dependence between earnings and attrition. For example, some copulas allow for symmetric positive or negative dependence (e.g. Gaussian) but cannot model tail dependence, whereas others allow only for upper or lower tail dependence (e.g. Gumbel and Clayton). Plackett and Frank copulas have proved popular in empirical work because they are flexible; they model the association between the two margins with a single parameter and they are comprehensive in that they can model both positive and negative association between the two margins by varying the dependence parameter.

We have no a priori restrictions on the dependence parameter. When, however, any particular specification conflicts with the data, our experience suggests that the maximum likelihood estimation will often fail or estimate a boundary value of the dependence parameter. From among the specifications for which we obtain full estimates ${ }^{2}$, our preferred specification is selected using the Bayesian information criterion.

4.4.1. Copula-based estimation results. For the GP data, using a large number of combinations of margins and copulas, the preferred model(s) is one based on Student $t$ marginal for log(earnings) and probit (or logit) margin

\footnotetext{
${ }^{2}$ The most common instance of non-convergence, or convergence to a boundary point of the parameter space, seems to occur when the copula function places a restriction on the dependence parameter such as imposing positive dependence or right-tail dependence. We presume that the resulting estimates are not maximum likelihood and exclude them from the comparison set. However, the reader is cautioned that such cases may also arise from poor starting values or weak identification.
} 
for attrition. This is shown in column (6) of Table III. With these marginal distributions, all alternative copula models generate very similar log-likelihood values close to -4775.2 , which is significantly higher than obtained when the Student $t$ is replaced by either normal or logistic margins, combined using any of the previously mentioned copulas.

However, we note that the freely estimated degrees-of-freedom parameter is usually close to 2, a value for which the third and higher moments are undefined. For the selection equation, none of the models indicate evidence in favour of selection bias because of attrition; see the Wald test of independence in Table III. Not surprisingly, they all deliver similar estimates of the two equations. Note that the results in column (5) of Table III indicate attrition bias but the key annual-hours elasticity shows quite minor variation. The copula-based estimate of the elasticity is about 0.315 , which is lower than the typical estimate obtained under other specifications. However, because the estimates reported in Table III are based on samples of different sizes, the conclusion is not clear cut.

For the specialist data, the fits of copulas using the Student $t$ marginal for earnings were no better than those from alternative margins. Moreover, the estimated degrees-of-freedom parameter was typically significantly less than 2, indicating that the variance is undefined. To avoid this problematic outcome, we revert to the results based on logit (for attrition) and logistic (for log earnings) margins. With these margins, Plackett's copula was the best choice and is the basis of the results reported in column (6) of Table IV. The Wald test of independence between attrition and earnings is rejected for $p$-values less than 0.001. A similar conclusion also implied when the Gaussian copula (which fits less well) is used.

Note that the non copula-based estimates reported in column (5) in Table IV are also consistent with the finding of attrition bias. The estimated elasticity of earnings with respect to hours is about 0.104 , much smaller than for GPs and smaller than the estimates from the conventional selection models. Overall, these results favour the hypothesis of attrition-induced selection bias.

We further assess the sensitivity of our results to the length of the panel by leaving out data of the fourth year for the 2008 cohort and running same analyses on data from waves 1 to 3 . The coefficient estimates from using the shorter panel are very similar to those discussed earlier, suggesting that the length of the panel have little bearings on our findings. We also applied inverse probability weighting and both very similar results for both weighted and unweighted estimates.

\section{TOP-UP SAMPLES}

Annual top-up samples of doctors are added to the original 2008 cohort of the MABEL survey. From the second and subsequent waves, doctors who are new additions to the AMPCo database and have not previously been asked to participate, are invited to join the study. These doctors comprise largely of new entrants to the medical workforce, as well as doctors re-entering into active clinical practice in Australia (e.g. returning from overseas and extended leave). The size of new cohorts varies year to year. The number of respondents and response rates for 2009, 2010 and 2011 are 2124 (37.8 per cent), 1235 (30.5 per cent) and 1219 (38.3 per cent), respectively.

Attrition in the top-up samples is considerably higher compared with the 2008 cohort. For instance, 36.2 per cent of GPs and 34.3 per cent of specialists in the 2009 cohort drop out in the second year (Table A.4). For the 2010 cohort, the attrition rate after the first year is 54.9 per cent for GPs and 35.4 for specialists. This is not surprising as the analysis of non-response in the 2008 cohort shows that younger doctors are more likely to attrite from the survey.

Compared with the 2008 cohort, doctors in the top-up samples have lower mean annual earnings and hours worked and are more likely to be male, overseas trained, younger and practise in regional and remote areas (Table A.5). Comparing responders and non-responders in the top-up samples, non-responders have higher mean earnings and hours worked, are less likely to be female, are more likely to be overseas trained and self-employed and have longer response time in the preceding survey wave. 


\subsection{Estimates of elasticity on hours: top-up samples}

Despite the higher attrition in the top-up samples compared with the 2008 cohort, attrition does not appear to have a significant effect on the estimation of physician earnings equations using the top-up samples. Tables $\mathrm{V}$ and VI present the estimated hours elasticities for GPs and specialists for the pooled 2009-2010 cohorts. The results show that not only are the hours elasticities in the balanced and unbalanced panels quite similar, these estimates are also not very different compared with those obtained from the attrition model. This is observed even when the attrition models reject the null hypothesis that the wave-varying hazard is jointly equal to zero, suggesting the presence of attrition bias.

Table V. Earnings model of general practitioners - 2009-2010 cohorts

\begin{tabular}{|c|c|c|c|c|c|c|}
\hline & $\begin{array}{l}\text { Unbalanced: } \\
\text { fixed } \\
\text { effects }\end{array}$ & $\begin{array}{l}\text { (2) } \\
\text { Balanced: } \\
\text { fixed } \\
\text { effects }\end{array}$ & $\begin{array}{l}\text { (3) } \\
\text { Unbalanced: } \\
\text { first } \\
\text { differences }\end{array}$ & $\begin{array}{l}\text { (4) } \\
\text { Balanced: } \\
\text { first } \\
\text { differences }\end{array}$ & $\begin{array}{l}\text { (5) } \\
\text { Attrition } \\
\text { adjusted }\end{array}$ & $\begin{array}{c}\text { (6) } \\
\text { Copula } \\
\text { selection } \\
\text { model }\end{array}$ \\
\hline Coefficient on hours & $\begin{array}{c}0.618 \\
(0.095)\end{array}$ & $\begin{array}{c}0.669 \\
(0.115)\end{array}$ & $\begin{array}{c}0.613 \\
(0.141)\end{array}$ & $\begin{array}{c}0.636 \\
(0.174)\end{array}$ & $\begin{array}{c}0.576 \\
(0.129)\end{array}$ & $\begin{array}{c}0.448 \\
(0.112)\end{array}$ \\
\hline $\begin{array}{l}\text { Wave-varying attrition hazards: } \\
\text { Wald test of joint significance }\left(\chi^{2}\right) \\
\text { Wald test: } p \text {-value } \\
\text { Degrees of freedom }\end{array}$ & & & & & $\begin{array}{l}19.81 \\
0.000 \\
3\end{array}$ & \\
\hline $\begin{array}{l}\text { Dependence in copula model: } \\
\text { Wald test of independence } \\
\text { Wald test: } p \text {-value }\end{array}$ & & & & & & $\begin{array}{l}0.154 \\
0.694\end{array}$ \\
\hline Number of observations & 1190 & 577 & 435 & 342 & 526 & 883 \\
\hline
\end{tabular}

Robust-clustered standard errors used in columns (3) and (4). Bootstrapped standard errors in column (5). The total number of covariates is 15 and is less than the set of covariates for the 2008 cohort because of the smaller size of the top-up samples. Additional covariates include visa status, hospital work, self-employment, experience, states/territory and remoteness. The copula selection model in column (6) is estimated using the Stata program heckmancopula developed by Hasebe (2013). The preferred copula selection model is based on Student $t$ marginal for log earnings, logit marginal for attrition and the Plackett copula.

Table VI. Earnings model of specialists - 2009-2010 cohorts

\begin{tabular}{|c|c|c|c|c|c|c|}
\hline & $\begin{array}{l}\text { Unbalanced: } \\
\text { fixed } \\
\text { effects }\end{array}$ & $\begin{array}{l}\text { (2) } \\
\text { Balanced: } \\
\text { fixed } \\
\text { effects }\end{array}$ & $\begin{array}{l}\text { (3) } \\
\text { Unbalanced: } \\
\text { first } \\
\text { differences }\end{array}$ & $\begin{array}{l}\text { (4) } \\
\text { Balanced: } \\
\text { first } \\
\text { differences }\end{array}$ & $\begin{array}{c}(5) \\
\text { Attrition } \\
\text { adjusted }\end{array}$ & $\begin{array}{c}(7) \\
\text { Copula } \\
\text { selection } \\
\text { model }\end{array}$ \\
\hline Coefficient on hours & $\begin{array}{l}0.773 \\
(0.065)\end{array}$ & $\begin{array}{c}0.870 \\
(0.069)\end{array}$ & $\begin{array}{c}0.654 \\
(0.165)\end{array}$ & $\begin{array}{c}0.741 \\
(0.181)\end{array}$ & $\begin{array}{c}0.669 \\
(0.144)\end{array}$ & $\begin{array}{c}0.375 \\
(0.161)\end{array}$ \\
\hline $\begin{array}{l}\text { Wave-varying attrition hazards: } \\
\text { Wald test of joint significance }\left(\chi^{2}\right) \\
\text { Wald test: } p \text {-value } \\
\text { Degrees of freedom }\end{array}$ & & & & & $\begin{array}{l}51.24 \\
0.000 \\
3\end{array}$ & \\
\hline $\begin{array}{l}\text { Dependence in copula model: } \\
\text { Wald test of independence } \\
\text { Wald test: } p \text {-value }\end{array}$ & & & & & & $\begin{array}{r}10.322 \\
0.000\end{array}$ \\
\hline Number of observations & 1017 & 520 & 402 & 312 & 456 & 709 \\
\hline
\end{tabular}

Robust-clustered standard errors used in columns (3) and (4). Bootstrapped standard errors in column (5). The total number of covariates is 8 and is less than the set of covariates for the 2008 cohort because of the smaller size of the top-up samples. Additional covariates include visa status, experience, self-employment, broad specialty groups, states/territory and remoteness. The copula selection model in column (6) is estimated using the Stata program heckmancopula developed by Hasebe (2013). The preferred copula selection model is based on logistic marginal for log earnings, logit marginal for attrition and the Gumbel copula. 


\subsection{Copula estimation results: top-up samples}

The copula-based estimates using the top-up samples data are summarised in Tables V and VI. These results are similar to those based on the 2008 cohort data in one respect. They indicate an absence of attrition-based selection bias in the GP sample and its presence in the specialist sample. Another pattern of results that is also repeated is that the hours elasticity based on the copula specification for specialists is nearly 40 per cent smaller than that based on the more conventional selection model.

\subsection{Using the top-up samples to handle attrition}

By design, the top-up samples in the MABEL survey are new doctors entering into the medical workforce and comprise predominately of younger doctors. We explained earlier that the main purpose of the top-up samples is to maintain the cross-sectional representativeness of the survey. However, although these samples are not strictly 'refreshment samples' in the sense of Hirano et al. (2001), they can potentially be used to address panel attrition in the original 2008 cohort. This is because the attritors in the original cohort consist of younger doctors, and by adding the top-up samples to the original cohort one would essentially be replacing the young attritors. Refinements can be made by replacing attritors with top-up doctors identified using propensity score matching (Dorsett, 2010).

There are a number of caveats. The inclusion of the young top-up doctors to the 2008 cohort may result in the over-representation of younger doctors. This is potentially a problem if the objective is to compare sample means of different variables, but is not an issue if one is estimating regressions (see Cameron and Trivedi (2005), Chapters 24.2 and 24.3; Solon et al. (2013)).

Secondly, if there is parameter heterogeneity in that the outcomes of interest for the young doctors vary systematically from those of the rest of the population, merging the top-up sample with the attrition-impacted sample may result in a misspecification that would affect the test of the MAR assumption. This can be tested, as we did, by estimating the earnings equation using only the 2008 cohort, using only the top-up samples and then using the combined pooled sample. The test is performed by calculating the Chow test statistics to test the restriction that the coefficients in the 2008 cohort and the top-up samples are equal. The test statistics are $F(8,3424)=5.08$ and $F(8,3706)=13.96$ for GPs and specialists, respectively, and one can reject the null hypothesis $^{3}$ at conventional levels that the earnings regression estimates for the 2008 cohort and the top-up samples are equal.

Finally, the top-up samples become top-up panels when followed over time and can itself suffer from attrition. It is therefore important that one systematically tests for attrition bias in the original panel, the top-up panels, as well as when these panels are combined.

\section{CONCLUSION}

In this paper, we assessed the nature and consequences of panel attrition in a unique longitudinal survey of medical doctors. While staying within the framework of selection on unobservables for modelling attrition bias, we have estimated both well-established, and some recently developed, econometrics methods. We find that copula-based selection models bring additional flexibility regarding distributional assumptions and dependence structure in the study of attrition. Specifically, we can account for fat-tails in the outcome distribution and asymmetric dependence in the selection mechanism. Further, we have analysed attrition bias in top-up samples and highlighted the potential issues that might arise from their use for controlling attrition bias.

We focus our inquiry on the econometric analysis of physician earnings as a case study of labour market outcomes in the medical sector. Our analysis suggests that the impact of attrition on inference about earnings of GPs is small. This conclusion applies to both the initial cohort and the subsequent top-up samples of GPs. Judged by the effect of attrition on estimates of the elasticity of earnings with respect to hours worked, the

\footnotetext{
${ }^{3}$ With the relatively large sample sizes analysed here, there is a greater tendency to reject the null hypothesis and detect significant differences; see Leamer (1978) for more details. We thank a reviewer for pointing this out.
} 
impact is larger for specialists. This is evidenced especially by the smaller point estimate from the copula model compared with the conventional selection models.

Users of panel data are frequently warned about the potential biases in inference that might result from attrition. Yet, many influential studies in the literature report that attrition does not lead to serious biases in the economic sense, even in the presence of statistical evidence of attrition bias, and large sample attrition (Fitzgerald et al., 1998; Neumark and Kawaguchi, 2004; Jones, 2007). Based on our results, we find that our study is in broad agreement with the general view on the consequences of attrition in panel studies. Such conclusions from individual case studies are consistent with the scenario in which attrition is well-predicted by regressors already included in the outcome equation, that is, the selection-on-observables model largely applies and hence attrition is well-controlled for. Our conclusions are but only slightly nuanced for the case of medical specialists, where there appears to be some evidence for an economically significant bias.

\section{APPENDIX}

Table A.1. Conditional attrition rates by quintiles of annual earnings and hours worked

\begin{tabular}{|c|c|c|c|c|c|c|c|c|c|c|}
\hline \multirow[b]{2}{*}{ Year } & \multicolumn{5}{|c|}{ Annual earnings } & \multicolumn{5}{|c|}{ Annual hours worked } \\
\hline & $\begin{array}{c}\text { Attrition } \\
\text { rate }(\%), \\
\text { 1st quintile }\end{array}$ & $\begin{array}{c}\text { Attrition } \\
\text { rate }(\%), \\
\text { 2nd quintile }\end{array}$ & $\begin{array}{c}\text { Attrition } \\
\text { rate }(\%), \\
\text { 3rd quintile }\end{array}$ & $\begin{array}{c}\text { Attrition } \\
\text { rate }(\%), \\
\text { 4th quintile }\end{array}$ & $\begin{array}{c}\text { Attrition } \\
\text { rate }(\%), \\
5 \text { th quintile }\end{array}$ & $\begin{array}{c}\text { Attrition } \\
\text { rate }(\%), \\
\text { 1st quintile }\end{array}$ & $\begin{array}{c}\text { Attrition } \\
\text { rate }(\%), \\
\text { 2nd quintile }\end{array}$ & $\begin{array}{c}\text { Attrition } \\
\text { rate }(\%), \\
\text { 3rd quintile }\end{array}$ & $\begin{array}{c}\text { Attrition } \\
\text { rate }(\%), \\
\text { 4th quintile }\end{array}$ & $\begin{array}{c}\text { Attrition } \\
\text { rate }(\%), \\
5 \text { th quintile }\end{array}$ \\
\hline & \multicolumn{10}{|c|}{ _ General practitioners } \\
\hline 2 & 17.4 & 22.3 & 20.9 & 21.3 & 16.8 & 17.8 & 21.0 & 21.6 & 24.1 & 19.4 \\
\hline 3 & 14.7 & 13.8 & 13.6 & 15.1 & 16.4 & 14.1 & 15.2 & 16.9 & 13.7 & 16.9 \\
\hline \multirow[t]{2}{*}{4} & 14.2 & 13.0 & 15.7 & 17.9 & 16.4 & 14.1 & 12.2 & 18.9 & 18.6 & 18.2 \\
\hline & & & & & — Specia & ts & & & & \\
\hline 2 & 18.9 & 16.7 & 16.8 & 16.5 & 19.6 & 17.8 & 21.5 & 18.2 & 18.1 & 21.7 \\
\hline 3 & 13.7 & 12.7 & 14.7 & 14.5 & 13.6 & 14.1 & 14.9 & 14.8 & 16.0 & 17.0 \\
\hline 4 & 16.0 & 10.8 & 14.6 & 12.3 & 14.2 & 16.4 & 11.4 & 15.2 & 15.0 & 15.8 \\
\hline
\end{tabular}

Table A.2. Attrition rates by earnings quintile and doctors' characteristics

\begin{tabular}{|c|c|c|c|c|c|c|c|c|c|c|c|c|}
\hline \multirow[b]{2}{*}{ Characteristics } & \multicolumn{6}{|c|}{ Earnings quintile: General practitioners } & \multicolumn{6}{|c|}{ Earnings quintile: Specialists } \\
\hline & $1 \mathrm{st}$ & 2nd & 3rd & 4th & 5 th & All & $1 \mathrm{st}$ & 2nd & 3 rd & 4th & 5 th & All \\
\hline Male & 19.4 & 20.8 & 17.1 & 19.5 & 16.2 & 18.2 & 16.4 & 14.4 & 16.9 & 14.5 & 15.7 & 15.5 \\
\hline Female & 14.4 & 14.8 & 17.2 & 16.0 & 18.3 & 15.6 & 16.7 & 12.5 & 11.9 & 15.2 & 20.0 & 14.7 \\
\hline \multicolumn{13}{|c|}{ Australian medical school } \\
\hline Yes & 15.0 & 15.8 & 15.6 & 16.9 & 14.8 & 15.6 & 15.5 & 12.6 & 14.9 & 14.4 & 15.9 & 14.6 \\
\hline No & 18.8 & 21.4 & 22.0 & 22.3 & 21.8 & 21.4 & 21.0 & 18.0 & 18.4 & 15.2 & 16.8 & 17.7 \\
\hline \multicolumn{13}{|c|}{ Experience in years } \\
\hline$<10$ & 23.8 & 19.9 & 23.9 & 18.4 & 17.4 & 21.3 & 18.8 & 14.8 & 13.8 & 17.0 & 21.7 & 17.2 \\
\hline $10-19$ & 15.6 & 14.5 & 16.6 & 16.4 & 20.7 & 16.5 & 14.2 & 15.6 & 17.7 & 19.2 & 16.8 & 16.8 \\
\hline $20-29$ & 9.9 & 16.4 & 16.6 & 19.8 & 14.9 & 15.9 & 18.7 & 11.4 & 14.2 & 13.1 & 14.3 & 13.9 \\
\hline $30-39$ & 12.7 & 14.8 & 12.3 & 15.9 & 15.8 & 14.6 & 12.5 & 12.7 & 18.2 & 13.3 & 13.8 & 14.2 \\
\hline$\geq 40$ & 20.6 & 17.2 & 18.6 & 13.9 & 9.3 & 16.5 & 15.3 & 11.8 & 8.6 & 12.8 & 19.6 & 13.8 \\
\hline \multicolumn{13}{|l|}{ Self-employed } \\
\hline Yes & 20.2 & 18.9 & 16.2 & 18.1 & 15.2 & 17.1 & 15.7 & 12.7 & 15.7 & 16.0 & 15.4 & 15.3 \\
\hline No & 14.2 & 15.0 & 17.3 & 18.5 & 19.3 & 16.3 & 15.1 & 14.3 & 15.4 & 13.2 & 14.8 & 14.5 \\
\hline \multicolumn{13}{|c|}{ Ever changed postcode } \\
\hline Yes & 16.6 & 18.5 & 20.5 & 21.4 & 20.9 & 19.3 & 18.2 & 15.3 & 14.1 & 17.1 & 18.5 & 16.5 \\
\hline No & 13.9 & 15.2 & 15.2 & 17.0 & 15.7 & 15.4 & 15.0 & 13.7 & 15.5 & 14.0 & 15.4 & 14.5 \\
\hline \multicolumn{13}{|c|}{ Response time quartile } \\
\hline $1 \mathrm{st}$ & 12.9 & 14.1 & 14.8 & 17.5 & 13.3 & 14.5 & 14.5 & 10.4 & 13.2 & 12.2 & 13.4 & 12.7 \\
\hline 2nd & 14.6 & 16.4 & 16.9 & 15.5 & 17.3 & 16.1 & 14.6 & 11.0 & 13.3 & 13.4 & 15.8 & 13.6 \\
\hline $3 \mathrm{rd}$ & 20.9 & 18.6 & 18.3 & 21.2 & 19.4 & 19.7 & 17.5 & 18.3 & 19.1 & 14.8 & 18.3 & 17.6 \\
\hline 4th & 17.1 & 23.8 & 24.5 & 21.9 & 21.6 & 21.5 & 22.4 & 19.5 & 21.1 & 23.1 & 19.7 & 21.2 \\
\hline
\end{tabular}


Table A.3. Baseline cohort characteristics in 2008 by attrition status

\begin{tabular}{|c|c|c|c|c|c|c|}
\hline & \multicolumn{3}{|c|}{ General practitioners } & \multicolumn{3}{|c|}{ Specialists } \\
\hline & Always in & Always out & Rejoin & Always in & Always out & Rejoin \\
\hline Mean annual earnings ('000) & 172.4 & 177.5 & 174.4 & 337.5 & 341.4 & 339.6 \\
\hline \multicolumn{7}{|l|}{ Quartiles ('000) } \\
\hline $\mathrm{q} 25$ & 91.0 & 100.0 & 96.0 & 190.0 & 180.0 & 181.2 \\
\hline q50 & 147.2 & 150.0 & 150.0 & 274.7 & 280.0 & 270.0 \\
\hline q75 & 220.0 & 240.0 & 230.7 & 400.0 & 400.0 & 400.0 \\
\hline Mean Annual hours & 2011.4 & $2121.8^{* * *}$ & 2070.6 & 2316.4 & 2349.5 & 2309.1 \\
\hline \multicolumn{7}{|l|}{ Quartiles } \\
\hline $\mathrm{q} 25$ & 1456.0 & 1664.0 & 1560.0 & 1976.0 & 1976.0 & 1950.0 \\
\hline q50 & 2080.0 & 2132.0 & 2080.0 & 2340.0 & 2340.0 & 2340.0 \\
\hline q75 & 2548.0 & 2600.0 & 2600.0 & 2756.0 & 2860.0 & 2750.0 \\
\hline Female $(\%)$ & 48.5 & $42.9^{* * *}$ & $42.9^{*}$ & 29.0 & $25.2^{* *}$ & 33.5 \\
\hline Temporary visa (\%) & 2.1 & $4.1^{* * *}$ & 1.1 & 0.7 & $1.5^{* *}$ & 0.9 \\
\hline Australian medical school & 82.3 & $72.5^{* * *}$ & $77.1^{* *}$ & 83.2 & 80.7 & 80.8 \\
\hline Fellow $(\%)$ & 57.4 & $54.5^{* *}$ & 57.4 & 96.6 & $94.7^{* *}$ & 95.2 \\
\hline Num. postgrad qualification & 0.6 & $0.5^{* * *}$ & $0.5^{*}$ & 0.2 & 0.2 & 0.2 \\
\hline Do hospital work (\%) & 24.3 & $27.8^{*}$ & 24.4 & - & - & - \\
\hline$\%$ time in clinical practice & - & - & - & 78.0 & $80.1^{* *}$ & 77.0 \\
\hline Self-employed $(\%)$ & 44.6 & 44.8 & 49.4 & 43.5 & $47.2^{*}$ & 41.4 \\
\hline \multicolumn{7}{|l|}{ Experience in years $(\%)^{a}$} \\
\hline$<10$ & 10.8 & $14.3^{* *}$ & $16.4^{* * *}$ & 14.7 & 13.6 & $23.7^{* * *}$ \\
\hline $10-19$ & 23.1 & 21.2 & 26.2 & 15.8 & $18.5^{*}$ & 18.3 \\
\hline $20-29$ & 36.2 & 34.4 & 33.0 & 35.8 & 34.8 & $28.2^{* * *}$ \\
\hline $30-39$ & 23.7 & 22.5 & $16.7^{* * *}$ & 24.3 & 23.2 & $19.8^{* *}$ \\
\hline$\geq 40$ & 6.1 & 7.5 & 7.7 & 9.4 & 9.9 & 9.9 \\
\hline$\overline{\text { Major city }(\%)}$ & 64.7 & 65.8 & 60.4 & 83.1 & 83.3 & $88.3^{* *}$ \\
\hline Inner regional $(\%)$ & 21.2 & 19.3 & 23.2 & 13.4 & 13.1 & $8.7^{* *}$ \\
\hline Outer regional, remote $(\%)$ & 14.1 & 14.9 & 16.4 & 3.5 & 3.5 & 3.0 \\
\hline Time to response (days) & 29.8 & $35.6^{* * *}$ & $35.7 * * *$ & 35.6 & $40.0^{* * *}$ & $45.2^{* * *}$ \\
\hline Number of observations & 1698 & 783 & 336 & 1896 & 810 & 333 \\
\hline
\end{tabular}

Significantly different from 'Always in':

*** $1 \%$,

** $5 \%$,

* $10 \%$.

${ }^{a}$ For specialists, the first two experience categories are $<15$ years, and $15-19$ years.

Table A.4. Responders and attritors in Medicine in Australia: Balancing Employment and Life - 2009 and 2010 cohorts

\begin{tabular}{|c|c|c|c|c|c|c|c|c|c|}
\hline $\begin{array}{l}\text { Year } \\
\text { (Cohort attritors }\end{array}$ & $\begin{array}{c}\text { Number of } \\
\text { doctors }\end{array}$ & $\begin{array}{l}\text { Clinical } \\
\text { practice }\end{array}$ & $\begin{array}{l}\text { Non-clinical } \\
\text { practice }\end{array}$ & $\begin{array}{c}\text { Total } \\
\text { responders }\end{array}$ & $\begin{array}{l}\text { Survival } \\
\text { rate }(\%)\end{array}$ & $\begin{array}{c}\text { Total } \\
\text { attritors }\end{array}$ & $\begin{array}{c}\text { Conditional } \\
\text { attrition } \\
\text { rate }(\%)\end{array}$ & $\begin{array}{c}\text { Cumulative } \\
\text { attrition } \\
\text { rate }(\%)\end{array}$ & Rejoiners \\
\hline \multicolumn{10}{|l|}{ (2009 cohort) } \\
\hline 1 & 543 & 543 & & & 100 & & & & \\
\hline 2 & 343 & 334 & 9 & 343 & 63.2 & 200 & 36.2 & 36.2 & \\
\hline $\begin{array}{l}3 \\
(2010 \text { cohort })\end{array}$ & 302 & 283 & 19 & 302 & 55.6 & 241 & 16.2 & 44.4 & 57 \\
\hline 1 & 448 & 448 & & & 100 & & & & \\
\hline 2 & 243 & 225 & 18 & 243 & 45.1 & 205 & 54.9 & 54.9 & \\
\hline \multicolumn{10}{|l|}{ (2009 cohort) } \\
\hline 1 & 484 & 484 & & & 100 & & & & \\
\hline 2 & 318 & 305 & 13 & 318 & 65.7 & 166 & 34.3 & 34.3 & \\
\hline $\begin{array}{l}3 \\
(2010 \text { cohort })\end{array}$ & 303 & 295 & 8 & 303 & 62.6 & 181 & 12.8 & 37.4 & 50 \\
\hline 1 & 370 & 370 & & & 100 & & & & \\
\hline 2 & 239 & 230 & 9 & 239 & 64.6 & 131 & 35.4 & 35.4 & \\
\hline
\end{tabular}


Table A.5. Characteristics of 2008 cohort and 2009-2010 top-up samples by attrition status

\begin{tabular}{|c|c|c|c|c|c|c|c|c|}
\hline & \multicolumn{4}{|c|}{ General practitioners } & \multicolumn{4}{|c|}{ Specialists } \\
\hline & \multicolumn{2}{|c|}{ Always in } & \multicolumn{2}{|c|}{ Always out } & \multicolumn{2}{|c|}{ Always in } & \multicolumn{2}{|c|}{ Always out } \\
\hline & 2008 & $2009-2010$ & 2008 & $2009-2010$ & 2008 & $2009-2010$ & 2008 & $2009-2010$ \\
\hline Mean annual earnings ('000) & 172.4 & $143.3^{*}$ & 176.6 & $168.1^{\dagger}$ & 337.5 & $245.6^{*}$ & 340.9 & 236.0 \\
\hline Mean Annual hours & 2016 & $1923.5^{*}$ & 2106.4 & $2048.4^{\dagger}$ & 2316.4 & $2156.0^{*}$ & 2337.7 & $2265.2^{\dagger}$ \\
\hline Female $(\%)$ & 48.5 & $61.5^{*}$ & 49.1 & $45.7^{\dagger}$ & 29.0 & $42.5^{*}$ & 25.5 & 37.1 \\
\hline Temporary visa (\%) & 2.1 & $19.3^{*}$ & 3.2 & 24.5 & 0.7 & $5.7^{*}$ & 1.3 & $9.8^{\dagger}$ \\
\hline Australian medical school & 82.3 & $46.9^{*}$ & 73.9 & $34.9^{\dagger}$ & 83.2 & $58.1^{*}$ & 80.8 & 50.2 \\
\hline Fellow $(\%)$ & 57.4 & $35.4^{*}$ & 55.4 & 34.2 & 96.6 & $60.5^{*}$ & 94.8 & 64.4 \\
\hline Num. postgrad qualification & 0.6 & $0.3^{*}$ & 0.5 & 0.3 & 0.2 & $0.2^{*}$ & 22.5 & $0.1^{\dagger}$ \\
\hline Do hospital work (\%) & 24.3 & 24.8 & 26.8 & 23.0 & - & - & - & - \\
\hline$\%$ time in clinical practice & - & - & - & - & 78.0 & $75.7^{*}$ & 79.2 & 75.7 \\
\hline Self-employed $(\%)$ & 44.6 & $10.2^{*}$ & 46.2 & $14.7^{\dagger}$ & 43.5 & $17.8^{*}$ & 45.5 & 19.0 \\
\hline Experience in years (\%) & & & & & & & & \\
\hline$<10$ & 10.8 & $41.1^{*}$ & 14.9 & 39.6 & 14.7 & $56.6^{*}$ & 16.5 & 58.5 \\
\hline $10-19$ & 23.1 & $33.9^{*}$ & 22.7 & 34.2 & 15.8 & 18.7 & 18.5 & 15.6 \\
\hline $20-29$ & 36.2 & $15.1^{*}$ & 34.0 & 15.8 & 35.8 & $17.8^{*}$ & 32.9 & 22.4 \\
\hline $30-39$ & 23.7 & $6.5^{*}$ & 20.7 & 7.6 & 24.3 & $5.4^{*}$ & 22.2 & $2.4^{\dagger}$ \\
\hline$\geq 40$ & 6.1 & $3.4^{*}$ & 7.6 & 2.9 & 9.4 & $1.5^{*}$ & 9.9 & 1.0 \\
\hline Major city (\%) & 64.7 & $55.5^{*}$ & 64.2 & 49.3 & 83.1 & 80.7 & 85.8 & 77.6 \\
\hline Inner regional (\%) & 21.2 & 24.0 & 20.5 & 29.1 & 13.4 & 13.9 & 11.8 & $19.5^{\dagger}$ \\
\hline Outer regional, remote $(\%)$ & 14.1 & $20.6^{*}$ & 15.4 & 21.6 & 3.5 & $5.4^{*}$ & 3.4 & 2.9 \\
\hline Time to response (days) & 29.8 & $91.9^{*}$ & 35.6 & $128.7^{\dagger}$ & 35.6 & 90.5 & 41.5 & $125.2^{\dagger}$ \\
\hline Number of observations & 1698 & 384 & 1119 & 278 & 1896 & 332 & 1143 & 205 \\
\hline
\end{tabular}

* Significantly different from 2008 cohort at $10 \%$.

†Significantly different from 2009-2010 'Always-in' at 10\%.

\section{ACKNOWLEDGEMENTS}

We thank Yuanyuan Gu, Andrew Jones, Chris Ryan, Anthony Scott and participants in presentations at the University of Melbourne and the Australasian Workshop on Econometrics and Health Economics. We are also grateful for the helpful comments and suggestions from two anonymous referees. Terence Cheng acknowledges financial support through a grant from the Faculty of Business and Economics at the University of Melbourne, where this research was conducted. This research used data from the MABEL longitudinal survey of doctors conducted by the University of Melbourne and Monash University (the MABEL research team). Funding for MABEL comes from the National Health and Medical Research Council (Health Services Research Grant: 2008-2011 and Centre for Research Excellence in Medical Workforce Dynamics: 2012-2016) with additional support from the Department of Health (in 2008) and Health Workforce Australia (in 2013). The MABEL research team bears no responsibility for how the data has been analysed, used or summarised in this research.

\section{REFERENCES}

Andreassen L, Di Tommaso ML, Strøm S. 2013. Do medical doctors respond to economic incentives? Journal of Health Economics 32: 392-409.

Baltagi BH, Bratberg E, Holmås TH. 2005. A panel data study of physicians' labor supply: the case of Norway. Health Economics 14(10): 1035-1045.

Cameron CA, Trivedi PK. 2005. Microeconometrics: Methods and applications. Cambridge University Press.: New York, NY.

Cheng TC, Scott AC, Jeon SH, Kalb G, Humphreys J, Joyce C. 2011. What factors influence the earnings of general practitioners and medical specialists? Evidence from The Medicine In Australia: Balancing Employment and Life survey. Health Economics 21(11): 1300-1317.

Dorsett R. 2010. Adjusting for non-ignorable sample attrition using survey substitutes identified by propensity score matching: an empirical investigation using labour market data. Journal of Official Statistics 26(1): 105-125. 
Fitzgerald J, Gottschalk P, Moffitt R. 1998. An analysis of sample attrition in panel data: The Michigan Panel Study of Income Dynamics. Journal of Human Resources 33(2): 251-299.

Gravelle H, Hole AR, Santos R. 2011. Measuring and testing for gender discrimination in physician pay: English family doctors. Journal of Health Economics 30(4): 660-674.

Hasebe T. 2013. Copula-based maximum-likelihood estimation of sample-selection models. The Stata Journal 13(3): 547-573.

Hausman JA, Wise DA. 1979. Attrition bias in experimental and panel data: the Gary income maintenance experiment. Econometrica: 455-473.

Hirano K, Imbens GW, Ridder G, Rubin DB. 2001. Combining panel data sets with attrition and refreshment samples. Econometrica 69(6): 1645-1659.

Ikenwilo D, Scott A. 2007. The effects of pay and job satisfaction on the labour supply of hospital consultants. Health Economics 16(12): 1303-1318.

Jones AM. 2007. Panel data methods and applications to health economics, In Palgrave Handbook of Econometrics.

Jones AM, Koolman X, Rice N. 2004. Health-related attrition in the BHPS and ECHP: using inverse probability weighted estimators in nonlinear models. Journal of the Royal Statistical Society: Series A.

Joyce CM, Scott A, Jeon S-H, Humphreys J, Kalb G, Witt J, Leahy A. 2010. The "Medicine in Australia: Balancing Employment and Life" (MABEL) longitudinal survey-Protocol and baseline data for a prospective cohort study of Australian doctors' workforce participation. BMC Health Services Research 10(1): 1-10.

Leamer EE. 1978. Specification Searches: Ad Hoc Inference with Nonexperimental Data. Wiley: New York.

Morris S, Goudie R, Sutton M, Gravelle H, Elliott R, Hole AR, Ma A, Sibbald B, Skåtun D. 2011. Determinants of General Practitioners' wages in England. Health Economics 20(2): 147-160.

Neumark D, Kawaguchi D. 2004. Attrition bias in labor economics research using matched cps files. Journal of Economic and Social Measurement 29(4): 445-472.

Nijman T, Verbeek M. 1992. Nonresponse in panel data: the impact on estimates of a life cycle consumption function. Journal of Applied Econometrics 7(3): 243-257.

Ridder G. 1992. An empirical evaluation of some models for non-random attrition in panel data. Structural Change and Economic Dynamics 3(2): 337-355.

Rizzo JA, Blumenthal D. 1994. Physician labor supply: do income effects matter? Journal of Health Economics 13(4): 433-453.

Sæther EM. 2005. Physicians labour supply: the wage impact on hours and practice combinations. Labour 19(4): 673-703.

Sasser AC. 2005. Gender differences in physician pay tradeoffs between career and family. Journal of Human Resources 2: 477-504.

Schurer S, Kuehnle D, Scott A, Cheng TC. 2012. One man's blessing, another woman's curse? Family factors and the gender-earnings gap of doctors. Institute for the Study of Labor Discussion Paper No. 7017.

Smith MD. 2003. Modelling sample selection using Archimedean copulas. The Econometrics Journal 6(1): 99-123.

Solon G, Haider SJ, Wooldridge J. 2013. What are we weighting for? National Bureau of Economic Research Working Paper 18859.

Trivedi P, Zimmer D. 2007. Copula modeling: an introduction for practitioners. Foundation and Trends in Econometrics 1(1): $1-111$.

Wooldridge JM. 2010. Econometric Analysis of Cross Section and Panel Data. The MIT Press.

Yan W, Li J, Scott A, Cheng TC, Sivey P, Leahy A. 2013. MABEL user manual: wave 4 release. 


\section{Author Query Form}

\section{Journal: Health Economics}

Article: HEC_3206

Dear Author,

During the copyediting of your paper, the following queries arose. Please respond to these by annotating your proof with the necessary changes/additions.

- If you intend to annotate your proof electronically, please refer to the E-annotation guidelines.

- If you intend to annotate your proof by means of hard-copy mark-up, please use the standard proofreading marks in annotating corrections. If manually writing corrections on your proof and returning it by fax, do not write too close to the edge of the paper. Please remember that illegible mark-ups may delay publication.

Whether you opt for hard-copy or electronic annotation of your proof, we recommend that you provide additional clarification of answers to queries by entering your answers on the query sheet, in addition to the text mark-up.

\begin{tabular}{|l|l|l|}
\hline Query No. & Query & Remark \\
\hline AQ1 & $\begin{array}{l}\text { AUTHOR: Please check that authors and their affiliations are } \\
\text { correct. }\end{array}$ & \\
\hline AQ2 & $\begin{array}{l}\text { Author: “Independent and identically distributed.” Is this the } \\
\text { correct definition for i.i.d.? Please change if this is incorrect. }\end{array}$ & \\
\hline AQ3 & $\begin{array}{l}\text { Author: "Instrumental variable or generalized method of } \\
\text { moments.” Are these the correct definitions for IV and GMM, } \\
\text { respectively? Please change if these are incorrect. }\end{array}$ & \\
\hline AQ4 & $\begin{array}{l}\text { AUTHOR: Please provide volume number for Hausman and Wise } \\
\text { 1979. }\end{array}$ & \\
\hline AQ5 & $\begin{array}{l}\text { AUTHOR: Please provide publisher name, city location and page } \\
\text { range for Jones 2007. }\end{array}$ & \\
\hline AQ6 & $\begin{array}{l}\text { AUTHOR: Please provide volume number and page range for } \\
\text { Jones } \text { et al. 2004. }\end{array}$ & \\
\hline AQ7 & AUTHOR: Please provide city location for Wooldridge 2010. & \\
\hline
\end{tabular}


Required software to e-Annotate PDFs: Adobe Acrobat Professional or Adobe Reader (version 7.0 or above). (Note that this document uses screenshots from Adobe Reader $\mathrm{X}$ )

The latest version of Acrobat Reader can be downloaded for free at: http://get.adobe.com/uk/reader/

Once you have Acrobat Reader open on your computer, click on the Comment tab at the right of the toolbar:

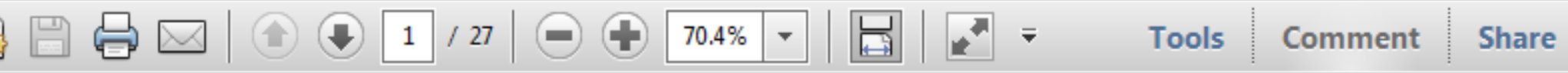

This will open up a panel down the right side of the document. The majority of tools you will use for annotating your proof will be in the Annotations section, pictured opposite. We've picked out some of these tools below:

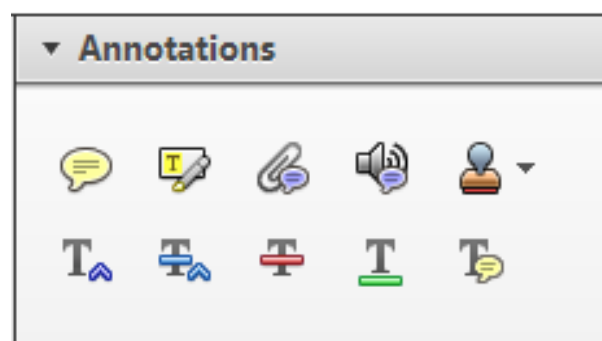

1. Replace (Ins) Tool - for replacing text.

Strikes a line through text and opens up a text box where replacement text can be entered.

How to use it

- Highlight a word or sentence.

- Click on the Replace (Ins) icon in the Annotations section.

- Type the replacement text into the blue box that appears.

Idard tramework for the analysis of $\mathrm{m}$ icy-Nevertheless, it also led to exog،

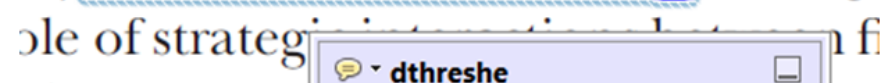
aber of comp 08/06/2011 15:58:17 is that the s1 nain compo: be level, are exc nc

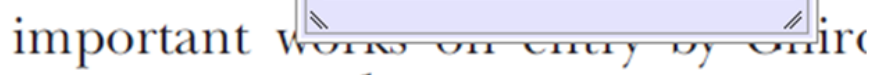
M heneferth) ${ }^{1}$ we anen the "hlarl $\mathrm{l}$

3. Add note to text Tool - for highlighting a section to be changed to bold or italic.

T Highlights text in yellow and opens up a text box where comments can be entered.

\section{How to use it}

- Highlight the relevant section of text.

- Click on the Add note to text icon in the Annotations section.

- Type instruction on what should be changed regarding the text into the yellow box that appears.

namic responses of mark ups ent with the VAR evidence

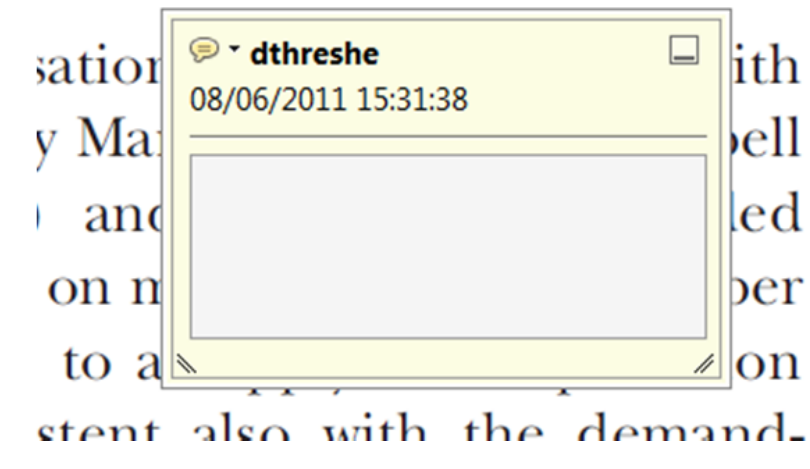

2. Strikethrough (Del) Tool - for deleting text.

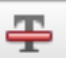

Strikes a red line through text that is to be deleted.

How to use it

- Highlight a word or sentence.

- Click on the Strikethrough (Del) icon in the Annotations section.

there is no room tor extra prohts al c ups are zero and the number of ret) values are not determined by Blanchard and Kiyotaki (1987), sfect competition in general equilil ts of aggregate demand and supply lassical framework assuming monol eph on evorenous number of firme

4. Add sticky note Tool - for making notes at specific points in the text.

Marks a point in the proof where a comment needs to be highlighted.

How to use it

- Click on the Add sticky note icon in the Annotations section.

- Click at the point in the proof where the comment should be inserted.

- Type the comment into the yellow box that appears.

iaisu airu suppiy sirucks. hivsl ui

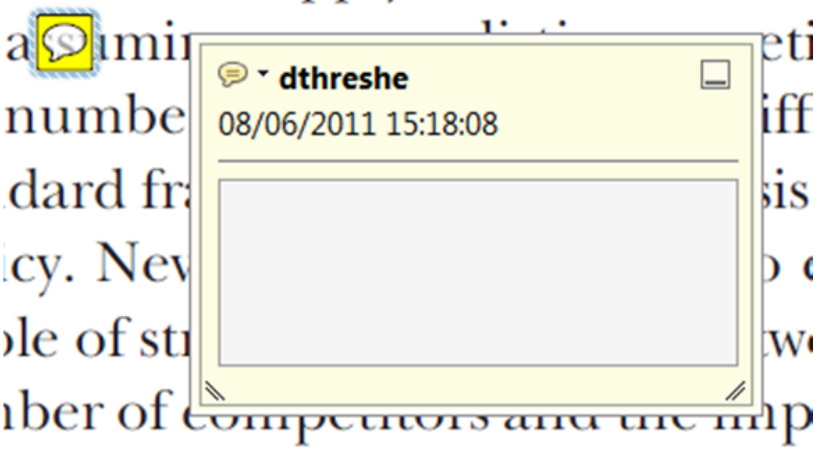

is that the structure of the secto. 
5. Attach File Tool - for inserting large amounts of text or replacement figures.

Inserts an icon linking to the attached file in the appropriate pace in the text.

How to use it

- Click on the Attach File icon in the Annotations section.

- Click on the proof to where you'd like the attached file to be linked.

- Select the file to be attached from your computer or network.

- Select the colour and type of icon that will appear in the proof. Click OK.

E N D

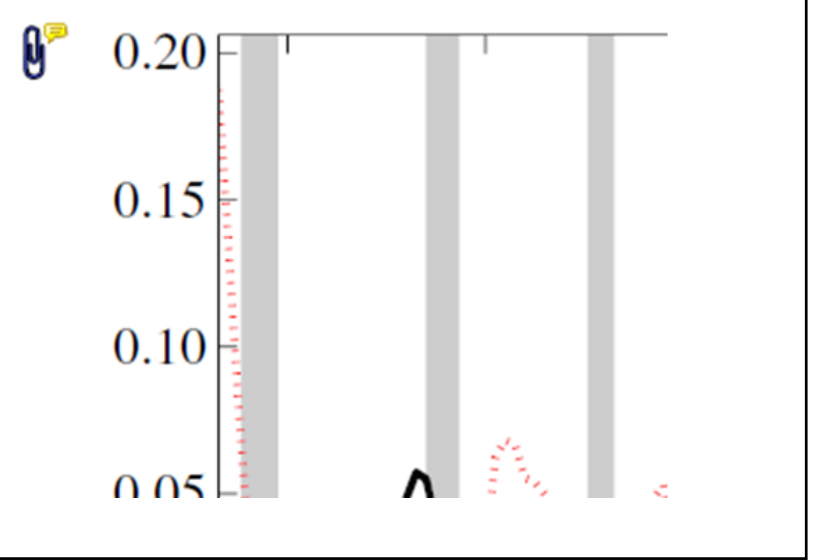

6. Add stamp Tool - for approving a proof if no corrections are required.

- Inserts a selected stamp onto an appropriate place in the proof.

\section{How to use it}

- Click on the Add stamp icon in the Annotations section.

- $\quad$ Select the stamp you want to use. (The Approved stamp is usually available directly in the menu that appears).

- Click on the proof where you'd like the stamp to appear. (Where a proof is to be approved as it is, this would normally be on the first page).

or the business cycie, starting with the on perfect competition, constant ret

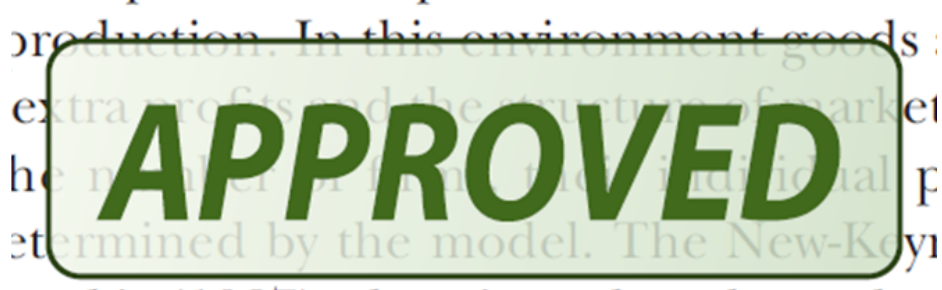
otaki (1987), has introduced produc general equilibrium models with nomin:

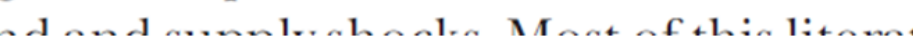

- Drawing Markups

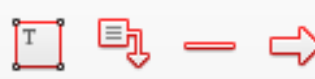

$0 \bigcirc \sqrt{6} \otimes$

\section{How to use it}

- Click on one of the shapes in the Drawing Markups section.

- Click on the proof at the relevant point and draw the selected shape with the cursor.

- To add a comment to the drawn shape, move the cursor over the shape until an arrowhead appears.

- Double click on the shape and type any text in the red box that appears.
7. Drawing Markups Tools - for drawing shapes, lines and freeform annotations on proofs and commenting on these marks.

Allows shapes, lines and freeform annotations to be drawn on proofs and for comment to be made on these marks.

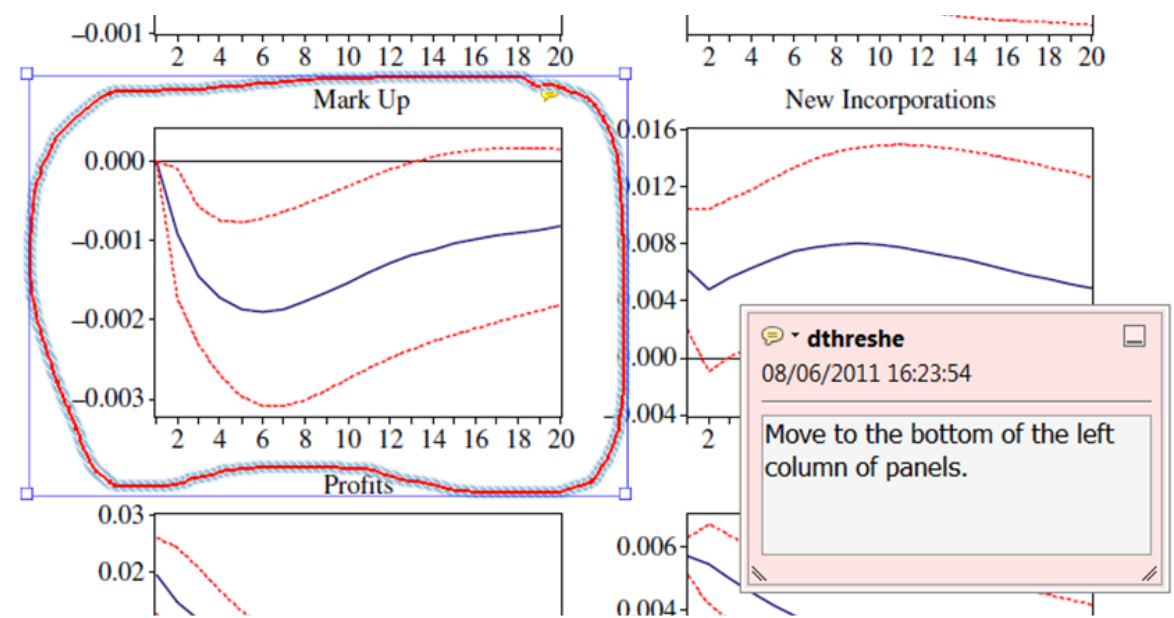

For further information on how to annotate proofs, click on the Help menu to reveal a list of further options:

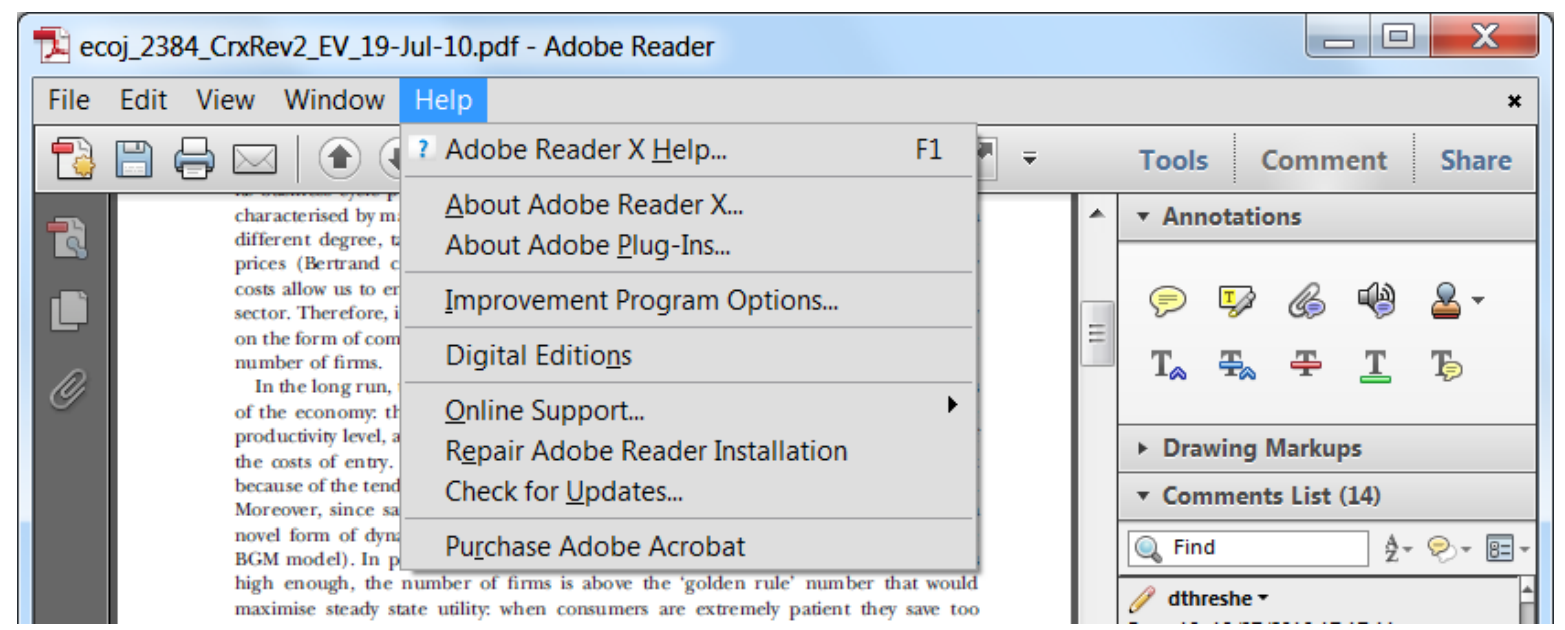




\section{University Library}

\section{- M M N E R VA A gateway to Melbourne's research publications}

Minerva Access is the Institutional Repository of The University of Melbourne

Author/s:

Cheng, TC; Trivedi, PK

Title:

ATTRITION BIAS IN PANEL DATA: A SHEEP IN WOLF'S CLOTHING? A CASE STUDY BASED ON THE MABEL SURVEY

Date:

2015-09-01

Citation:

Cheng, T. C. \& Trivedi, P. K. (2015). ATTRITION BIAS IN PANEL DATA: A SHEEP IN WOLF'S CLOTHING? A CASE STUDY BASED ON THE MABEL SURVEY. HEALTH ECONOMICS, 24 (9), pp.1101-1117. https://doi.org/10.1002/hec.3206.

Persistent Link:

http://hdl.handle.net/11343/118222 